\title{
An Analysis of Yield Gap and Some Factors of Cocoa (Theobroma cacao) Yields in Ghana
}

\author{
Aneani F. ${ }^{1}$ \& Ofori-Frimpong K. ${ }^{1}$ \\ ${ }^{1}$ Cocoa Research Institute of Ghana, New Tafo-Akim, Ghana \\ Correspondence: Aneani F., Cocoa Research Institute of Ghana, New Tafo-Akim, Ghana. Tel: \\ 233-024-476-3516. E-mail: franeani@yahoo.com
}

Received: March 25, 2013 Accepted: September 10, 2013 Online Published: September 23, 2013

doi:10.5539/sar.v2n4p117 URL: http://dx.doi.org/10.5539/sar.v2n4p117

\begin{abstract}
Although cocoa productivity has recently been increasing in Ghana, it is still low compared with that of other countries such as Cote d'Ivoire and Malaysia. This situation has been attributed to the low adoption of cocoa production technologies. The study was aimed at analysing the yield gap as well as some cocoa yield factors. Cross-sectional socio-economic survey was conducted in six (6) cocoa growing districts: Nkawie, Goaso, Enchi, Oda, Twifo Praso/Assin Fosu and Hohoe. A structured questionnaire was employed in the collection of data from 300 respondents who were randomly chosen with multi-stage cluster sampling technique. The yield gaps and their proportion to yield potentials were estimated using data from the survey and on-station trials. The findings indicated an experimental yield gap of $1553.4 \mathrm{~kg} \mathrm{ha}^{-1}$, accounting for $82.1 \%$ of the experimental yield potential whereas farmer-based yield gap was $1537.2 \mathrm{~kg} \mathrm{ha}^{-1}$, also accounting for $82.0 \%$ of the farmer (survey) yield potential. The Ordinary Least Square (OLS) regression analysis indicated that frequency of spraying fungicides against black pod disease, spraying insecticides against capsids, weeding of cocoa farms, cocoa variety planted by farmer, area of cocoa farm and total cocoa production variables had a significant impact on cocoa yield. It is recommended that the Government should encourage cocoa farmers, through pragmatic measures, to adopt improved technologies for enhancing productivity instead of focusing on excessive land expansion which eventually leads to low productivity.
\end{abstract}

Keywords: cocoa, survey, farmers, yield gap, regression, Ghana

\section{Introduction}

Increasing agricultural productivity or yield is critical to economic growth and development. This can be achieved by using improved agricultural technologies and management systems. Yield refers to production per unit area. Yield gap is calculated by subtracting achieved average yield from the yield potential (Lobell, Cassman, \& Field, 2009). Yield potential of a crop is the yield obtained when it is grown in a suitable environment of adequate moisture and nutrients, without pest and disease problems (Gommes, 2006; Lobell et al., 2009). Lobell et al. (2009) indicated that, given the area as well as cropping season, yield potential depends on amount of moisture, sunshine intensity, temperature, crop-sowing date, maturity rating, plant population, and light-use efficiency of photosynthesis. Understanding yield gap is very crucial for it can assist in crop yield predictions since yield potential shows the probable future productivity to be achieved. Also, information on determinants of yield gap can be used in policy interventions for enhancing crop production. Conventionally, yield potential is measured by simulation model of plant metabolic activities which produce the likely highest yield (Gommes, 2006; Lobell et al., 2009). According to Lobell et al. (2009), the "model" yield gap ( $\left.\mathrm{YG}_{\mathrm{M}}\right)$, "experimental" yield gap ( $\left.\mathrm{YG}_{\mathrm{E}}\right)$, and "farmer" yield gap $\left(\mathrm{YG}_{\mathrm{F}}\right)$ are linked as follows: $\mathrm{YG}_{\mathrm{F}} \leq \mathrm{YG}_{\mathrm{E}} \leq \mathrm{YG}_{\mathrm{M}}$. $\mathrm{YG}_{\mathrm{F}}$ can be smaller compared to $\mathrm{YG}_{\mathrm{E}}$ as well as $\mathrm{YG}_{\mathrm{M}}$ when farmers fail to maintain soil fertility and control pests and diseases. The alternative methods are surveys on past maximum estimated on-station yields and competitive yields obtained by farmers.

Crop production depends on the crop area and crop yield so to increase production one has to raise either of them. Lobell et al. (2009) noted that there is a higher probability to expand the land area towards crop growth due to congenial environment. However, scientists and policy makers aim at improving yields to reduce excessive land extensions, with a view to ensure food security and conservation of the ecosystem services, and to protect the environment. Although yield increasing technologies may have negative outcomes on the environment, they remain important in achieving sustainable food security (Lobell et al., 2009). 
Although cocoa productivity has recently been increasing, it is still low compared with that of other countries such as Cote d'Ivoire and Malaysia. Currently, the national average is around $400 \mathrm{~kg} \mathrm{ha}^{-1}$. This higher yield was achieved through the implementation of Cocoa Disease and Pest Control (CODAPEC) and Cocoa High Technology (Hi-tech) programmes by the Ghana Cocoa Board (COCOBOD) in response to the low adoption of Cocoa Research Institute of Ghana (CRIG) technologies by the cocoa farmers (Henderson \& Jones, 1990; Donkor, Henderson, \& Jones, 1991; MASDAR, 1998; Aneani, Anchirinah, Asamoah, \& Owusu-Ansah, 2007). Maximum yields of more than $1000 \mathrm{kgha}^{-1}$ and about $2000 \mathrm{kgha}^{-1}$ had been achieved on farmers' farms (Aneani et al., 2007) and on-station trials with fertilizer, and hybrid cocoa (Ahenkorah, Akrofi, \& Adri, 1974; Ofori-Frimpong, Afrifa, \& Appiah, 2006), respectively. This clearly indicates the extent of yield gap that needs to be closed. Maredia and Minde (2002) concluded that the productivity gap in Africa is heavily determined by non-technological constraints (infrastructure, policies, input/output markets, and adverse climatic conditions) which reduced profitability and adoption of new technologies. Also, the rate of adoption of a new technology depends on the degree of risk and uncertainty associated with it, capital requirement, agricultural policies, and the socio-economic characteristics of farmers.

The current study was a component of a survey conducted for the Ghana Cocoa Farmers' Newspaper Project established by CRIG and Cadbury International Limited with the aim of delivering improved cocoa production practices to farmers to raise their productivities. COCOBOD which plays a regulatory role in the cocoa industry in Ghana has realized the need to increase cocoa production by using productivity-increasing technologies. It is also important to examine the possibility of realizing the yield potential through the use of improved production practices recommended by CRIG. This requires knowledge of specific constraints to productivity in cocoa cropping systems. Thus, the main purpose of this study was to analyze the yield gap and some factors of cocoa yield. Hence, the following research questions are posed: Is there a cocoa yield gap? What are the factors of cocoa yields?

\section{Methodology}

\subsection{Study Areas}

The six selected cocoa districts of Ghana, in which the survey was carried out include Nkawie, Goaso, Enchi, Oda, Twifo Praso/AssinFosu and Hohoe (Figure1). From Table1, the lowest mean rainfall of these districts was 945.7 $\mathrm{mm}$ and the highest was $2000 \mathrm{~mm}$ whilst the mean temperature recorded was in the range of $22-34{ }^{\circ} \mathrm{C}$ per annum. The altitude above sea level was in the spectrum of 61-890 m. Generally, the areas were located in the moist semi-deciduous rain forest zone, with agriculture, commerce, lumbering and quarrying being the major socio-economic activities engaged in by the populace. The main cash crops cultivated within the study areas include cocoa (T. cacao), citrus (Citrus sinensis), oil palm (Elaeis guineensis) whilst the food crops were maize (Zea mays), cassava (Manihot esculenta), rice (Oryza sativa), yam (Dioscorea spp.), and plantain (Musa sapientum).

Table 1. Profile of the districts selected for the survey

\begin{tabular}{|c|c|c|c|c|c|c|c|}
\hline Region & District & $\begin{array}{l}\text { Land } \\
\text { area } \\
\left(\mathrm{km}^{2}\right)\end{array}$ & $\begin{array}{l}\text { Rainfall } \\
(\mathrm{mm})\end{array}$ & $\begin{array}{l}\text { Temperature } \\
\left({ }^{\circ} \mathrm{C}\right)\end{array}$ & $\begin{array}{l}\text { Altitude } \\
\quad(\mathrm{m})\end{array}$ & Vegetation & $\begin{array}{l}\text { Socio-economic } \\
\text { activities }\end{array}$ \\
\hline Ashanti & Nkawie & 894.2 & 1077 & $27-31$ & 77 & $\begin{array}{l}\text { Semi-deciduous rain } \\
\text { forest }\end{array}$ & $\mathrm{F}$ and $\mathrm{C}$ \\
\hline Brong-Ahafo & Goaso & 1093.7 & 1108 & $23-33$ & 305 & $\begin{array}{l}\text { Semi-deciduous rain } \\
\text { forest }\end{array}$ & $\mathrm{F}$ and $\mathrm{C}$ \\
\hline Western & Enchi & 2638.0 & 1429 & $22-34$ & 300 & $\begin{array}{l}\text { Moist semi-deciduous } \\
\text { rain forest }\end{array}$ & $\mathrm{F}, \mathrm{L}, \mathrm{SSM}$ and $\mathrm{C}$ \\
\hline Eastern & $\begin{array}{l}\text { Akim } \\
\text { Oda }\end{array}$ & 1090.0 & 1784 & $25-27$ & 61 & $\begin{array}{c}\text { Semi-deciduous rain } \\
\text { forest }\end{array}$ & $\underset{\mathrm{C}}{\mathrm{F}, \mathrm{L}, \mathrm{SSM}, \mathrm{Q} \text { and }}$ \\
\hline Central & $\begin{array}{l}\text { Twifo } \\
\text { Praso }\end{array}$ & 1199.0 & 1077 & $26-30$ & 91 & $\begin{array}{l}\text { Semi-deciduous rain } \\
\text { forest }\end{array}$ & $\mathrm{F}, \mathrm{L}, \mathrm{SSM}, \mathrm{Q}$ and $\mathrm{C}$ \\
\hline Volta & Hohoe & 1403.0 & 1526 & $22-34$ & 890 & $\begin{array}{l}\text { Moist semi-deciduous } \\
\text { rain forest }\end{array}$ & $\mathrm{F}$ and $\mathrm{C}$ \\
\hline
\end{tabular}

Source: Adapted from Aneani et al. (2012).

Note: $\mathrm{F}=$ Farming, $\mathrm{C}=$ Commerce, $\mathrm{L}=$ Logging, $\mathrm{SSM}=$ Small-scale mining, $\mathrm{Q}=$ Quarrying. 


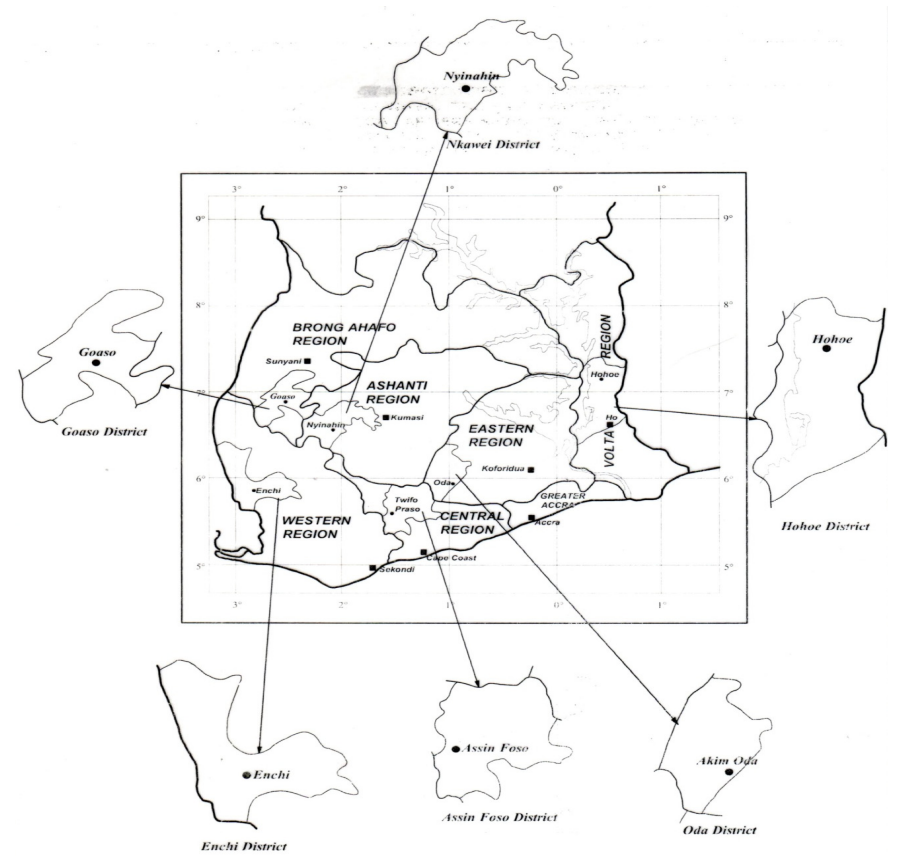

Figure 1. Map indicating the various districts where the base line survey on the Ghana cocoa farmers news paper was conducted

\subsection{Sampling and Data Collection}

The researchers conducted a cross-sectional survey of selected cocoa-growing districts. The survey started in March and ended in May, 2006 with a total of 300 respondents randomly chosen employing multi-stage sample selection procedure for interviews. The choice of the number of respondents was dependent on precision of 0.94 calculated from a variability of 16.3 years in an age variable of a former survey (Aneani \& Asamoah, 2004) and on obtaining a broad representative sample. The sample frame which was a list containing farmers' names was obtained from Licensed Buying Companies (LBCs) operating in the villages surveyed. A four-stage sampling technique was used. The first stage involved the entire six cocoa producing regions to help generalize the key results over the population. The six districts were selected in the second stage whereas 30 villages and 300 respondents were chosen randomly in the third and fourth stages, respectively (Table 2).

Table 2. Selected farmers and communities for the survey

\begin{tabular}{llcc}
\hline Region & District & Number of Villages per District & Number of Cocoa Farmers \\
\hline Eastern & Oda & 5 & 50 \\
Ashanti & Nkawie & 5 & 50 \\
Brong-Ahafo & Goaso & 5 & 50 \\
Central & TwifoPraso/AssinFosu & 5 & 50 \\
Western & Enchi & 5 & 50 \\
Volta & Hohoe & 5 & 50 \\
Total & & 30 & 300 \\
\hline
\end{tabular}

Data were gathered from the respondents with pretested structured questionnaire that contained items like demographic characteristics of the interviewed farmers, cocoa production technologies and limitations, cocoa output/yield, etc. A response rate of $100 \%$ was obtained since all the 300 cocoa farmers were interviewed.

\subsection{General Farmer and Farm Characteristics}

Table 4 summarizes the demographic and farm characteristics of the respondents. The farmers were advanced in age with an average of 51.5 years whilst their average farming experience was 19.6 years. A mean of 3.3 adult household members worked on the cocoa farm. Farmers had poor educational standard with $52.0 \%$ of them reaching middle school and $21.5 \%$ having no education at all. For gender, males accounted for $80.0 \%$ whereas 
females, $20.0 \%$. Farmers tended to operate small farms with average size of 3.0 ha, yield of $337.9 \mathrm{~kg} \mathrm{ha}^{-1}$ and cocoa production of $797.4 \mathrm{~kg}$. The variability in cocoa production figures obtained from farmers' passbooks was high. This can be attributed to the diverse temporal and spatial rainfall quantity and distribution. An average cocoa income was GH $\not 17.68$ which also had a high variability caused by that of cocoa production.

\subsection{On-Station Trial}

The data from which the experimental cocoa yield potential was derived was generated from an on-station trial (Ofori-Frimpong et al., 2006). This experiment was mainly aimed at studying the response of new cocoa hybrids to phosphate $(\mathrm{P})$ and potassium $(\mathrm{K})$ fertilizers, with a specific objective to establish the yield potentials of some new cocoa hybrids under $\mathrm{P}$ and $\mathrm{K}$ fertilization. The trial was carried out at the Cocoa Research Institute of Ghana (CRIG) at New Tafo-Akim for 17 years, but 4-year yield data were used for the analysis. The experimental design used was a split-plot with five cocoa varieties as main plots and $3^{2} \mathrm{P} \mathrm{K}$ fertilizer factorials as subplots. The fertilizer treatments and cocoa hybrid varieties used in the trial were as follows:

$\mathrm{P}_{1}=100 \mathrm{~kg} \mathrm{P}_{2} \mathrm{O}_{5} \mathrm{ha}^{-1}, \mathrm{P}_{2}=200 \mathrm{~kg} \mathrm{P}_{2} \mathrm{O}_{5} \mathrm{ha}^{-1}, \mathrm{P}_{3}=400 \mathrm{~kg} \mathrm{P}_{2} \mathrm{O}_{5} \mathrm{ha}^{-1}$

$\mathrm{K}_{1}=60 \mathrm{~kg} \mathrm{~K}_{2} \mathrm{O} \mathrm{ha}{ }^{-1}, \mathrm{~K}_{2}=120 \mathrm{~kg} \mathrm{~K}_{2} \mathrm{O} \mathrm{ha}^{-1}, \mathrm{~K}_{3}=180 \mathrm{~kg} \mathrm{~K}_{2} \mathrm{O} \mathrm{ha}^{-1}$

$\mathrm{V} 1=\mathrm{T} 63 / 967 \times \mathrm{T} 17 / 524, \mathrm{~V} 2=\mathrm{T} 85 / 799 \times \mathrm{Pa} 7 / 808, \mathrm{~V} 3=\mathrm{T} 85 / 799 \times \mathrm{Na} 729, \mathrm{~V} 4=\mathrm{T} 63 / 971 \times$ Amel, $\mathrm{V} 5=\mathrm{T} 63 / 971$ x T60/887.

\subsection{Analytical Framework}

The survey data was subjected to descriptive and inferential analyses. The experimental yield gap was calculated as the difference between the estimated national average yield and the maximum experiment-based yield potential achieved in on-station trials at CRIG (Ofori-Frimpong et al., 2006). The farmer yield gap was also computed as the difference between the maximum farmer yield potential and the estimated national average yield which were derived from the yield data of current socio-economic survey (Aneani et al., 2007). The farmer yield potential was estimated as the maximum of the yields achieved by the respondents on their farms. The factors of cocoa yields were analysed using a regression model.

\subsection{Empirical Model of the Factors of Cocoa Yields}

The factors of actual cocoa yield were investigated by regression analysis using the Ordinary Least Square (OLS) technique as employed by Gommes (2006) as well as Strother and Panda (2011). The OLS technique was employed since the dependent variable was a continuous random variable and the independent variables were either continuous or categorical, taking into consideration regression modeling assumptions. The linkages among cocoa productivity and its factors were modeled to establish the important policy variables. Generally, linear function, $\mathrm{f}($.$) , was specified as follows:$

$\mathrm{Y}=\mathrm{f}(\mathrm{X} 1, \mathrm{X} 2, \mathrm{X} 3, \mathrm{X} 4, \mathrm{X} 5, \mathrm{X} 6, \mathrm{X} 7, \mathrm{X} 8, \mathrm{X} 9, \mathrm{X} 10, \mathrm{X} 11, \mathrm{X} 12, \mathrm{e})$

Where,

$\mathrm{Y}=$ Cocoa productivity $\left(\mathrm{kg} \mathrm{ha}^{-1}\right)$

$\mathrm{X} 1$ = Age of the cocoa farm (years) (-); The older the farm, the higher the probability that cocoa output and productivity will reduce, causing discouragement in farm maintenance.

$\mathrm{X} 2$ = Frequency of spraying against black pod disease by cocoa farmer (+); Black pod disease can sweep rapidly through a farm destroying more than half of the crop in the wet and humid weather (Idachaba \& Olayide, 1976; MASDAR, 1998). It has been recommended to farmers by CRIG to spray against black pod with fungicides, 6-9 times per annum to ensure effective control of the disease. Thus, it was assumed that high spraying frequencies could lead to effective control of black pod, resulting in increased output and yield.

X3 = Frequency of spraying against capsids by cocoa farmer (+); capsids attack the cocoa trees by feeding on the succulent foliage and in extreme cases causing death, leading to reduction in cocoa output and yield. It has been recommended by CRIG for farmers to spray against capsids with insecticides 4 times per annum to ensure the effective control of the pests. Therefore, it was posited that high spraying frequencies results in effective capsid control, leading to output and yield increases.

X4 = Education level of cocoa farmer was categorized into literates and illiterates $(+)$ : We predicted a positive relationship between this variable and cocoa yield since an educated farmer can evaluate the improved production practices and make informed technical and economical choices to increase adoption.

X5 = Fertilizer application. The fertilizer variable was assumed to be a dummy variable which takes the value 1 
if the cocoa farmer applied fertilizer to his/her farm, and otherwise takes the value $0(+)$ : In Ghana, prolonged cultivation of cocoa on a piece of land has been found to result in soil fertility decline due to soil nutrient mining (Appiah, Ofori-Frimpong, \& Afrifa, 2000). Thus, applying fertilizer to such soils can replenish the depleted soil nutrients and hence, increase cocoa output and yield.

X6 = Quantity of fungicides applied to cocoa farm measured in satchets (+): It is hypothesized that the higher the quantity of fungicides applied, the more effective will be the control of black pod disease which tends to decrease cocoa output and yield.

X7 = Farm area quantified in hectares (-): Cocoa farm size was assumed to negatively influence yield because land expansion might increase cocoa output, but in Ghana extensive cocoa cultivation is associated with a decline in soil fertility, leading to low productivity over time (MASDAR, 1998; Seini, 2002).

$\mathrm{X} 8=$ Frequency of extension visits by the extension officer $(1=$ no visit, $2=$ at least one visit $)(+)$ : The more frequent the exposure of a farmer to extension information of new improved production practices, the more likely he can be convinced to adopt the appropriate technologies to increase yield.

$\mathrm{X} 9$ = Cocoa production measured in kilogramme $(+)$ : Cocoa production is predicted to be positively related to yield as revenue from increased output could be used to buy yield-increasing resources for cocoa farming.

$\mathrm{X} 10=$ Rainfall measured in millimeters (+): A positive relationship was expected to exist between rainfall and yield because water is required by the plant for nutrient absorption and photosynthesis to ensure proper plant growth and development. However, excessive rainfall could impact negatively on yield.

$\mathrm{X} 11$ = Cocoa variety planted by cocoa farmer. The cocoa variety variable which was considered a continuous was scored by giving a value 1 if the farmer planted Hybrid variety, a value 2 if the farmer planted

Amazon and a value 3 if the farmer planted Amelonado variety (+): Hybrid cocoa, which is early-bearing and high-yielding and currently recommended to farmers, is an improved variety over the Amazon that is also superior to the Amelonado type. Thus, it is anticipated that a farmer planting hybrid seeds or having a hybrid farm could produce higher cocoa yield than those with Amazon and Amelonado farms, other things being equal.

$\mathrm{X} 12=$ Frequency of weeding of the cocoa farm by the cocoa farmer (+): Weeds normally compete with the cocoa tree for water and nutrients. Therefore, the higher the weed control frequency, the better for the plant to develop and produce more output and yield.

$\mathrm{e}=$ Error term: It is assumed the error term is independent and normally distributed with mean zero $(0)$ and known variance $\left(\sigma^{2}\right)$

\section{Results}

\subsection{Yield Gap Analysis}

The analysis of variance indicated a statistically significant interaction between fertilizer and cocoa variety $\left(F_{0.05}\right.$ $(60,240)=3.442, P=0.0001)$. For the four-year data, the mean of $1288.55 \pm 319.2 \mathrm{~kg} \mathrm{ha}^{-1}$ was obtained from the $\mathrm{P}_{2} \mathrm{~K}_{3}$ fertilizer combination and cocoa variety $2\left(\mathrm{~V}_{2}\right)$, with a range between 88.9 and $1891.3 \mathrm{~kg} \mathrm{ha}^{-1}$. Table 3 shows the experimental potential, farmer potential and estimated national average yields of cocoa in Ghana estimated with data from the survey and trial. The experimental yield potential for cocoa was estimated using the results from an on-station trial in which an attempt was made to include treatments for optimal management to prevent nutrient, pest and disease stresses. This yield potential was estimated as the maximum value of the interaction effects because of the significant interaction between fertilizer and hybrid cocoa. The experimental cocoa yield gap was estimated to be $1553.4 \mathrm{kgha}^{-1}\left(1891.3-337.9=1553.4 \mathrm{~kg} \mathrm{ha}^{-1}\right)$. The percentage of yield gap to experimental yield potential was $82.1 \%((1553.4 / 1891.3) \times 100)$ whilst the percentage of estimated national average yield to experimental yield potential was $17.9 \%((337.9 / 1891.3) \times 100)$. The analysis of variance of the cocoa yield response of fertilizer and cocoa variety planted by the farmers indicated a statistically significant interaction between fertilizer and hybrid cocoa variety $\left(\mathrm{F}_{0.05}(3,218)=2.91 ; P<0.05\right)$ with mean of $405.2 \pm 348.7 \mathrm{~kg} \mathrm{ha}^{-1}$ having a range between $78.1 \mathrm{~kg} \mathrm{ha}^{-1}$ and $1875.1 \mathrm{~kg} \mathrm{ha}^{-1}$ whilst the main effects were not significant. Similarly, the farmer potential was also estimated as the maximum value of the interaction effects of fertilizer and hybrid cocoa variety planted by farmers. The farmer yield gap was also computed as the difference between the farmer yield potential and the estimated national average yield which were derived from the yield data of a socio-economic survey (Aneani et al., 2007). The farmer yield gap was estimated to be $1537.2 \mathrm{~kg} \mathrm{ha}^{-1}((1875.1-337.9)=1537.2)$. The percentage of farmer yield gap to its yield potential was $82.0 \%((1537.2 / 1875.1) \times 100)$ whereas the percentage of estimated national average yield to farmer yield potential was $18.0 \%((337.9 / 1875.1) \times 100)$. The experimental-based yield gap was observed to be greater than the farmer-based one as postulated by theory 
although the simulated-based yield gap was not estimated for comparison because of unavailability of its yield potential. This is because no simulation study has been done on cocoa yield in Ghana.

Table 3. Yield gap estimated using two different methods for estimating yield potential for cocoa in Ghana

\begin{tabular}{cccc}
\hline Item & Experimental potential & Farmer potential & National average \\
\hline Estimated cocoa yield $\left(\mathrm{kgha}^{-1}\right)$ & 1891.3 & 1875.1 & 337.9 \\
Yield gap $\left(\mathrm{kgha}^{-1}\right)$ & 1553.4 & 1537.2 & - \\
Percentage yield gap to potential (\%) & 82.1 & 82 & - \\
Percentage estimated average yield & 17.9 & 18 & - \\
\hline
\end{tabular}

Table 4. Descriptive summary of the variables used in ordinary least square (OLS) regression analysis

\begin{tabular}{lccccc}
\hline Variable & Mean & Std. Dev. & Min & Max & N \\
\hline Actual cocoa yield (kilogramme per hectare). & 337.9 & 255.2 & 62.5 & 1953.1 & 238 \\
Frequency of weeding. & 2.4 & 0.7 & 1 & 6 & 298 \\
Frequency of spraying against black pod. & 1.8 & 1.6 & 0 & 8 & 289 \\
Frequency of spraying against capsids. & 1.9 & 1.3 & 0 & 6 & 292 \\
Age of cocoa farm (years). & 16.9 & 12.5 & 1 & 85 & 291 \\
Area of cocoa farm (hectares). & 2.9 & 2 & 1 & 10 & 232 \\
Cocoa variety planted & 1.8 & 0.9 & 1 & 3 & 242 \\
Quantity of fungicides applied to cocoa farm (satchet) & 30.2 & 19.8 & 5 & 98 & 100 \\
Total cocoa production (kilogrammes). & 797.4 & 442.9 & 218.8 & 2000.0 & 174 \\
Fertilizer application (with fertilizer $=33.1 \%$, without fertilizer $=66.9 \%)$ & & & 293 \\
Frequency of farm visits by the extension officer (no visit = 55.3\%, at least one visit = 44.7\%) & 293 \\
\hline
\end{tabular}

Table 5. Results of ordinary least square (OLS) regression analysis

\begin{tabular}{lccc}
\hline & \multicolumn{3}{c}{ Model: Cocoa Yield } \\
\hline Independent Variable & Coefficient & t-value & P-value \\
Constant & 224.331 & 3.058 & $0.003^{* * *}$ \\
Frequency of weeding & 55.085 & 2.385 & $0.019^{* *}$ \\
Frequency of spraying against black pod & -22.202 & -2.49 & $0.014^{* *}$ \\
Frequency of spraying against capsids & 24.033 & 2.392 & $0.018^{* *}$ \\
Fertilizer application & 25.013 & 0.827 & 0.41 \\
Cocoa variety planted & -28.051 & -2.044 & $0.043^{* *}$ \\
Age of cocoa farm (years) & 0.784 & 0.531 & 0.596 \\
Area of cocoa farm (hectares) & -67.486 & -10.228 & $0.000^{* * *}$ \\
Quantity of fungicides applied to cocoa farm (satchet) & -0.101 & -0.432 & 0.667 \\
Frequency of farm visits by the extension officer & -21.838 & -0.733 & 0.465 \\
Total cocoa production (kilogrammes) & 0.252 & 12.057 & $0.000^{* * *}$ \\
F-statistic $(10,125)=24.798$ & & & \\
R-squared $=0.665$ & & & \\
Adjusted R-squared = 0.638 & & & \\
Durbin-Watson $=1.920$ & & & \\
Sample size (n) = 136 & & & \\
\hline $05 * * *$ P $<0.01$ & & & \\
\hline
\end{tabular}

Note: $* * \mathrm{P}<0.05, * * * \mathrm{P}<0.01$. 
Table 4 contains the descriptive summary of the factors included the OLS model. From the regression outcomes (Table 5), the F-statistics of 24.798 was statistically significant $(P<0.01)$, indicating a joint influence of the independent variables on the dependent variable and that the model existed. The R-squared was 0.665 , implying that $66.5 \%$ of cocoa yield variation explained by the factors combined. Durbin-Waston statistics was 1.920 , showing no autocorrelation in the model. The constant term was significant $(P<0.01)$. Also, the following variables had a significant positive impact on the cocoa yield: frequency of spraying insecticides against capsids $(P$ $<0.05)$, frequency of weeding the cocoa farms $(P<0.05)$, and total cocoa production $(P<0.01)$. Other variables had significant negative impact on yield and these included frequency of spraying fungicides against black pod disease $(P<0.05)$, cocoa variety planted $(P<0.05)$, and area of cocoa farm $(P<0.001)$. However, age of the cocoa farm, fertilizer application, quantity of fungicides applied to cocoa farm, and frequency of farm visit by the extension officer, were statistically insignificant in explaining the variability in the annual cocoa yield levels $(P>$ $0.05)$.

For frequency of weeding, the positive coefficient means that increasing the number of times of weeding by one unit, increased cocoa yield by $55.09 \mathrm{~kg} \mathrm{ha}^{-1}$. Concerning black pod control, the negative coefficient implies that as the frequency of black pod control increased by one unit, cocoa yield decreased by $22.20 \mathrm{~kg} \mathrm{ha}^{-1}$. This negative relationship was unexpected because of improper fungicide application for black pod control. The analysis indicated a positive relationship between capsid spraying frequency and cocoa yield as expected. As the spraying frequency increased by one unit, there was a corresponding increase in cocoa yield by $24.03 \mathrm{~kg} \mathrm{ha}^{-1}$.

Planting or having a poor cocoa variety reduced yield by $28.1 \mathrm{~kg} \mathrm{ha}^{-1}$. The negative relationship between cocoa yield and cocoa variety was expected. The varieties were scored with the most preferred given a lowest score and the least preferred the highest. Therefore, a choice made towards the least preferred cocoa variety resulted in a decrease in cocoa yield, that is, the poor cocoa varieties produced lower yields.

In addition, there was a negative relationship between farm size and cocoa yield. With an increase in farm size by one hectare, cocoa yield decreased by $67.49 \mathrm{~kg} \mathrm{ha}^{-1}$. Finally, the analysis showed a positive relationship between cocoa yield and cocoa production and this outcome was expected.

The quantity of insecticides applied to cocoa farm, rainfall, and education level of the farmer variables were removed from the cocoa yield model due to multicollinearity and less variation in the data.

\section{Discussion}

The results indicate that there is a large yield gap to close given the yield potential that can be achieved by researchers or farmers. This is because of relatively poor adoption concerning CRIG's technologies by the cocoa farmers. This study has shown that although farmers controlled weeds, pests and diseases, and applied fertilizer to the farms, farm maintenance was inadequate leading to yields below the potential. Farmers attributed the inadequate farm maintenance to poor access to the production resources such as access to cash/credit, labour, spraying machines and so on (Aneani et al., 2007; MASDAR, 1998). The regression analysis indicated that the frequency of spraying fungicides against black pod disease, frequency of spraying insecticides against capsids, frequency of weeding cocoa farms, cocoa variety planted by the farmer, area of cocoa farm and total cocoa production variables had a significant impact on cocoa yield.

\subsection{Yield Potential and Yield Gap}

The results indicated that the experimental yield gap was greater than the farmer one and this is consistent with the theory that $\mathrm{YG}_{\mathrm{F}} \leq \mathrm{YG}_{\mathrm{E}} \leq \mathrm{YG}_{\mathrm{M}}$, that is, farmer-based yield gap being less than that of the experiment-based yield gap which in turn is less than the model-based one. The experimental yield potential was also greater than that achieved on farmers' farms. This difference could be explained that on-station trials are conducted under well controlled conditions while the farmer potential is achieved under the influence of various biotic, abiotic and edaphic factors. For instance, Aggarwal, Herbbar, Venugopalan, Rani, and Bala (2008) attributed the challenges in measuring yield potential to changes in soil moisture which depended on rainfall and the soil type.

Lobell et al. (2009) showed global variations in yield gap estimates.

\subsection{Weeding Frequency}

Regular control of weeds eliminates competition for plant nutrients in the soil, and pests and diseases from attacking the cocoa plant. Cocoa farmers have been advised to weed their farms regularly as excess weeds compete for nutrients, encourage pests and black pod disease, etc. MASDAR (1998) showed that cocoa farmers tended to weed their farms 2.3 times per year as compared to 2.0 times as discovered by Aneani et al. (2007). In addition, COCOBOD (1995) and MASDAR (1998) reported respective figures of $43.6 \%$ and $49.0 \%$, being the proportion of cocoa farmers who brushed their farms twice as compared with $48.0 \%$ indicated by Aneani et al. (2007). Further, 
MASDAR (1998) reported that about $6.5 \%$ of the cocoa farmers interviewed weeded their farms 4 times as compared with 3.4\% indicated by Aneani et al. (2007). Even in this study about $1.0 \%$ of the farmers did not weed their farms at all. These pieces of evidence buttress the fact that cocoa farmers are not adhering to the recommendation by CRIG that cocoa farms should be weeded at least 4 times in a year. The policy implication is that farmers ought to be made aware about the importance of weeds and their regular control to ensure healthy farms which can produce higher yields.

The evidence provided by Aneani et al. (2007) indicated that few cocoa farmers (5.7\%) used weedicides such as Roundup, Grammozone, Atrazine, Caliherb, etc. to control weeds on their farms, with the majority (92.7\%) relying on manual weeding. The use of weedicides, as is being promoted in the media, would help to reduce drastically the tedium involved in manual weed control. However, the environmental impact of the use of these chemicals should be assessed (Owusu-Manu, 1985). To obtain the weedicides will not be a problem since most of the farmers can access them at the farmers' input stores and the open market.

Additionally, studies on other crops have demonstrated the relationship between weeding frequency and yield. Dimes, Muza, Malunga and Snapp (2001) observed in their simulation experiment of maize grain yield response to weeding frequency that yield increased with increasing weeding frequency. Also, Chikoye, Manyong, Carsky, Ekeleme, Gbehounou and Ahanchede (2002) reported that higher weeding frequency manually or by using herbicide was better than lower one in weed control, leading to yield increase. Truong Thi Ngoc Chi, Hossain and Flor Palis (2004) reported that weed and rice disease control influenced rice yield, that is, rice field without weeds and diseases increased rice productivity.

\subsection{Frequency of Spraying Against Black Pod Disease}

The negative relationship was unexpected and might be attributed to improper and inefficient application of the fungicides and the spraying difficulty which leads to the poor control of the black pod disease (Asante, Aneani, Asamoah, \& Baah, 2002). Black pod disease which occurs in all the cocoa growing regions is an important disease of cocoa. It can destroy more than half the crop in wet and humid weather (Idachaba \& Olayide, 1976; MASDAR, 1998). It was observed that chemical control of black pod disease by farmers was not adequately practised (COCOBOD, 1995; MASDAR, 1998). Aneani et al. (2007) observed that $29.3 \%$ of the cocoa farmers interviewed did not spray against the disease. The non-adoption of the recommended control practices was attributed to the tediousness of the spraying and the cost of the chemicals given that the farms were to be sprayed 5 to 9 times to ensure effective control. The reduction in the percentage of farmers who did not spray their farms was due to the CODAPEC programme, that is, the mass spraying exercise instituted by the Government. Farmers relied solely on the programme instead of spraying to supplement the two sprays of the CODAPEC.

\subsection{Frequency of Spraying Against Capsids (Mirids)}

The analysis indicated a positive relationship between capsid spraying frequency and cocoa yield as expected. Excessive capsid attack of the cocoa trees can lead to disastrous consequences for productivity (Entwistle, 1985; MASDAR, 1998). Therefore, controlling the pests can increase cocoa yield. In Ghana, the most important cocoa pests are capsids and research at CRIG indicated that these insects can reduce cocoa yields by $25 \%$ in 3 years in severe attacks (Owusu-Manu, 1985). It is recommended that cocoa trees be sprayed one to four times a year on both young and mature farms. A farming system survey conducted in 1998 showed that $51 \%$ of the interviewed farmers sprayed two or more times a year against capsids. The socio-economic survey conducted concurrently observed that capsid control by the farmers was far less than the recommended as $34 \%$ of the farmers did not spray at all (MASDAR, 1998). As a comparison, Aneani et al. (2007) indicated that about $64.7 \%$ of the farmer respondents sprayed two or more times per year against capsids while $20.5 \%$ did not spray at all. These findings are consistent with that provided by earlier adoption studies conducted by CRIG that cocoa farmers did not control capsids adequately (Donkor et al., 1991; Henderson \& Jones, 1990). This development has also implication for the CODAPEC programme being implemented by COCOBOD.

\subsection{Cocoa Variety Planted}

Cocoa variety planted was found as a key factor influencing cocoa productivity. The negative relationship observed means that planting Amelonado variety instead of hybrid might not improve cocoa yield. This phenomenon can be attributed to the genetic variations among the cocoa varieties. The result is consistent with that of Edwin and Masters (2005) that the adoption of a new cocoa variety increased cocoa yield by at least $42 \%$. Cocoa hybrids of various classes have been widely available at least for the past 35 years or more in Ghana. The hybrids are popular with the farmers because they are early-bearing, high-yielding and produce pods throughout the year. However, the impact desired from the seed gardens has not been achieved partly because farmers use too many seeds by planting at stake and at far higher densities than advised by the extension agency and the institutional 
problem of the Seed Production Unit (SPU) of COCOBOD. This situation has implication for the COCOBOD's programme of replanting all cocoa farms of more than 30 years with hybrid varieties.

Some farmers often make greater use of seeds from pods taken from their own neighbours' farms as indicated by about $38.1 \%$ of the farmers (Aneani et al., 2007). These seeds rarely produce well-yielding trees since they are not true-to-type as they are not artificially pollinated and need to be replaced. However, Aneani and others observed that more cocoa farmers (about 50.0\%) sourced their seeds from the seed gardens. Although use of hybrid varieties are on the increase in Ghana, the relatively low yielding Amelonado variety still makes up more than $12 \%$ of the tree stock in pure and mixed stands (MASDAR, 1998) as compared to about $11.0 \%$ in the Baseline Survey (Aneani et al., 2007). Intercropping has been observed to enhance productivity through proper arrangement and control diseases. Li et al. (2009) reported that intercropping improved yield by providing favourable environment. This means that intercropping cocoa varieties with other compatible crops could increase cocoa productivity. The effect of cocoa varieties on yield is determined by how resistant the varieties are to diseases and pests (Tijani, 2005).

\subsection{Farm Size and Cocoa Production}

Farm size negatively influenced cocoa yield whilst there was a positive relationship between cocoa yield and cocoa production. Possible explanation of this outcome is that, in Ghana, most of the farmers establish their farms through clearing of the forest and burning the debris. This activity causes deforestation, land ruin, and depletion of soil nutrient (Quansah, Drechsel, Yirenkyi, \& Asante-Mensah, 2000). With the rapid population growth, to increase crop output is less possible by land extension to fresh areas. This activity causes deforestation, land ruin and depletion of soil nutrients, leading to low crop productivity (Ministry of Science and Environment, 2002; Seini, 2002). For instance, Wiredu, Mensah-Bonsu, Andah and Fosu (2010) also reported a significant inverse relationship between land productivity and land area under cocoa $(P<0.05)$ in Ghana. In a study to explain labour productivity of small-holder farmers in Nigeria, Okoye, Onyenweaku, Ukoha, Asumugha and Aniedu (2008) found farm size and household size to have a statistically significant negative relationship with labour productivity $(P<0.05)$. Also, Kiani (2008) and Thapa (2007) confirmed the hypothesis of inverse relationship between farm size and output per hectare. The forest depletion and environmental degradation can be ameliorated by increasing production per unit area of land, instead of excessive land expansion, by utilizing yield-increasing technologies such as regular weeding, pests and disease control, replenishing soil fertility to compensate for losses from harvesting and leaching, and pruning and shade management.

\subsection{Limitation and Future Research}

Lack of information on issues of environment, institutions, politics and socio-economy prevented the researchers from including them in the cocoa yield model. Thus, a research can be designed to capture the issues. Additional research need to be conducted on the effect of rainfall and temperature, etc. on cocoa yields since the attempt to model them failed.

\section{Conclusion and Recommendation}

The analysis has demonstrated that a cocoa yield gap of $1553.4 \mathrm{~kg} \mathrm{ha}^{-1}$ existed, accounting for $82.1 \%$ of the experimental potential whereas on farmers' farms a yield gap of $1537.2 \mathrm{~kg} \mathrm{ha}^{-1}$ existed, also accounting for $82.0 \%$ of the farmer potential. The regression analysis indicated that frequency of spraying fungicides against black pod disease, frequency of spraying insecticides against capsids, frequency of weeding cocoa farms, cocoa variety planted by farmer, area of cocoa farm and total cocoa production variable had a significant impact on cocoa yield. The indication of huge yield gap by this study challenges COCOBOD to encourage cocoa farmers through pragmatic measures to adopt the yield-increasing technologies of cocoa production to minimize excessive land expansion.

\section{Acknowledgements}

We wish to acknowledge Mr. L. K. Akuffo, Mr. S. Duodu, Mr. Dickson Agyapong and Mr. Patrick Zeal, of the Social Science and Statistics Unit (SSSU) of Cocoa Research Institute of Ghana (CRIG) for their immense contribution to this study. This paper, CRIG/02/2013/045/006, is published with the permission of the Executive Director, CRIG, Tafo.

\section{References}

Aggarwal, P. K., Herbbar, K. B., Venugopalan, M. V., Rani, S., \& Bala, A. (2008). Quantification of yield gap in rain-fed rice, wheat, cotton and mustard in India. Glob.Theme Agroecosyst. Rep., 43, Andhra Pradesh, India: Int. Crops Res. Inst. Semi-Arid Tropics (ICRISAT). 
Ahenkorah, Y., Akrofi, G. S., \& Adri, K. K. (1974). The end of the cocoa shade and manurial experiment at the Cocoa Research Institute of Ghana. Journal of Horticultural Science, 49, 43-51.

Aneani, F., \& Asamoah, M. (2004). Socio-economic Survey on Cocoa Fermentation in Ghana. Journal of the Ghana Science Association, 6(2), 90-97.

Aneani, F., Anchirinah, V. M., Asamoah, M., \& Owusu-Ansah, F. (2012). Adoption of some cocoa production technologies by cocoa farmers in Ghana. Sustainable Agricultural Research, 1(1), 103-117.

Aneani, F., Anchirinah, V. M., Asamoah, M., \& Owusu-Ansah, F. (2007). Baseline socio-economic and farm managements survey. A Final Report for the Ghana Cocoa Farmers' Newspaper Project. New Tafo-Akim: Cocoa Research Institute of Ghana (CRIG).

Appiah, M. R., Ofori-Frimpong, K., \& Afrifa, A. A. (2000). Evaluation of fertilizer application on some peasant cocoa farms in Ghana.Ghana Journal of Agricultural Science, 33, 183-190. http://dx.doi.org/10.4314/gjas.v33i2.1869

Asante, E. G., Aneani, F., Asamoah, M., \& Baah, F. (2002). A baseline survey to determine and compare farmer perceptions of cocoa black pod disease in P.megakarya and non-P megakarya endemic areas. A report submitted to the Management of CRIG, New TafoAkim: DFID (UK) CABI Bioscience, BakehamEgham, Survey, UK.

Chikoye, D., Manyong, V. M., Carsky, R. J., Ekeleme, F., Gbehounou, G., \& Ahanchede, A. (2002). Response of peargrass (Imperata cylindrical) to cover crops integrated with hand weeding and chemical control in maize and cassava. Crop Protection, 21, 145-156. http://dx.doi.org/10.1016/S0261-2194(01)00078-3

COCOBOD. (1995). Causes of recent decline in cocoa production in Ghana and measures to revamp the industry, Accra, Ghana: Ghana Cocoa Board (COCOBOD).

Dimes, J., Muza, L., Malunga, G., \& Snapp, S. (2001). Trade-off between investments in nitrogen and weeding: on-farm experimentation and simulation analysis in Malawi and Zimbabwe. Seventh Eastern and Southern Africa Regional Maize Conference, $11^{\text {th }}-15^{\text {th }}$ Feruary, 2001, 452-456.

Donkor, M. A., Henderson, C. P., \& Jones, A. P. (1991). Survey to quantify adoption of CRIG recommendations. Cocoa Research Institute of Ghana (CRIG), Farming Systems Unit Research Paper No. 3, 29.

Edwin, J., \& Masters, W. A. (2005). Genetic improvement and cocoa yields in Ghana. Expl. Agric., 41, 1-13. http://dx.doi.org/10.1017/S0014479705002887

Entwistle, P. F. (1985). Cocoa mirids (Capsids), cocoa production, present constraints and priorities for research, 67-69.

Gommes, R. (2006). Non-parametric crop yield forecasting, a didactic case study for Zimbabwe. Paper presented at the EU/JRC meeting on Remote Sensing Support to Crop Yield Forecast and Area Estimate, $30^{\text {th }}$ November $-1^{\text {st }}$ December, 2006, Stresa, Italy.

Henderson, C. P., \& Jones, A. P. (1990). Analysis of constraints to the adoption of CRIG recommendations in Offinso Districts: Results and Discussion. CRIG farming systems Unit Research, Paper No. 1 CRIG, Tafo, Ghana, 15.

Idachaba, F. S., \& Olayide, S. O. (1976). The economics of pesticides use in Nigerian agriculture. Lagos, Nigeria: Federal Department of Agriculture.

Kiani, A. K. (2008). Farm size and productivity in Pakistan. European Journal of Social Science, 7(2), 42-52.

Li, C., He, X., Zhu, S., Zhou, H., Wang, Y., Li, Y., ... Zhu, Y. (2009). Crop diversity for yield increase. PLoS ONE, 4 (11), e8049. http://dx.doi.org/10.1371/journal.pone.0008049

Lobell, D. B., Cassman, K. G., \& Field, C. B. (2009). Crop yield gaps: Their importance, magnitudes and causes. Annual Review of Environment and Resources, 34, 1-26. http://dx.doi.org/10.1146/annurev.environ.041008.093740

Maredia, K. M., \& Minde, J. I. (2002). Technology profitability and agricultural transformation: Concepts, evidence, and policy implications. In T. S. Jayne, I. J. Minde \& G. Argwings-Kodhek (Eds.), Perspective on Agricultural Transformation: A View from Africa, New York: Nova Science Publishers, Inc.

MASDAR. (1998). Socio-economic study. Accra, Ghana: MASDAR International Consultants/Ghana Cocoa Board (COCOBOD) 
Ministry of Science \& Environment. (2002). National Biodiversity Strategy for Ghana. Accra, Ghana: Ministry of Environment and Science.

Ofori-Frimpong, K., Afrifa, A. A., \& Appiah, M. R. (2006). The response of new cocoa hybrids to phosphate and potassium fertilizers, Rep. Cocoa Res. Inst., Ghana, 2005/2006, 38-43.

Okoye, B. C., Onyenweaku, C. E., Ukoha, O. O., Asumugha, G. N., \& Aniedu, O. C. (2008). Determinants of labour productivity on small-holder cocoa farmers in Anambra State, Nigeria. Scientific Research and Essay, $1,559-561$.

Owusu-Manu, E. (1985). The evaluation of the synthetic pyrethroids for the control of Distantiella theobroma Dist. (Hemiptera, Miridae) in Ghana. Proc. $9^{\text {th }}$ Int.CocoaRes.Conf., 1984, Lome, Togo, 535-538.

Quansah, C., Drechsel, P., Yirenkyi, B. B., \& Asante-Mensah, S. (2000). Farmers' perceptions and management of soil organic matter - a case study from West Africa. Nutrient Cycling in Agroforestry Systems, 61, 205- 213. http://dx.doi.org/10.1023/A:1013337421594

Seini, W. A. (2002). Agricultural growth and competitiveness under policy reforms in Ghana. Technical Publication No. 16, Institute of Statistical, Social and Economic Research (ISSER), University of Ghana, Legon, Accra, 1-11.

Strother, C. W., \& Panda, S. S. (2011). Soil moisture and peanut crop yield correlation study in Georgia with two contrasting precipitation years. Proceedings of the 2011 Georgia Water Resources Conference, held April 11-13, 2011, at the University of Georgia, USA.

Thapa Sridhar. (2007). The relationship between farm size and productivity: empirical evidence from the Nepalese mid-hills. MPRA Paper No.7638. http://mpra.ub.uni-muenchen.de/7638/1/mpra_paper_7638pdf

Tijani, A. A. (2005). Profitability of fungicide use decisions among cocoa farmers in south western Nigeria. J. Soc. Sci., 11(2), 165-171.

Troung Thi Ngoc Chi, Hossain, M., \& Flor Palis. (2004). Impact of integrated pest management: farmer field school (IPM-FSS) on farmers' insect pest management belief, attitude and practices (KAP) in Vietnam. Omonrice, 12,109-119.

Wiredu, A. N., Mensah-Bonsu, A., Andah, E. K., \& Fosu, K. Y. (2010). Improved technology and land productivity among smallholder cocoa farmers in Ashanti Region, Ghana. Poster presented at the Joint $3^{\text {rd }}$ African Association of Agricultural Economists (AAAE) and $48^{\text {th }}$ Agricultural Economists Association of South Africa (AEASA) Conference, Cape Town, South Africa, September, 2010.

\section{Copyrights}

Copyright for this article is retained by the author(s), with first publication rights granted to the journal.

This is an open-access article distributed under the terms and conditions of the Creative Commons Attribution license (http://creativecommons.org/licenses/by/3.0/). 